\title{
DISTROFIA MUSCULAR DE DUCHENNE EM MENINA COM TRANSLOCAÇÃO CROMOSSOMMICA
}

\author{
LINEU CESAR WERNECK* - SILVIA M. L. LEMOS**- NEIVA MAGDALENA***
}

RESUMO - Relato do caso de menina que apresentava clínica e laboratoriglmente elementos para o diagnóstico de distrofia muscular progressiva pseudo-hipertrófica de Duchenne, cuja investigação genética revelou translocação cromossômica $46, \mathrm{X}, \mathrm{t}(\mathrm{Bp}+, \mathrm{Xq}-)$. Foi feita revisão da IIteratura, enfatizando a importância dos métodos diagnósticos e a explicaçåo do aparecimento de casos de distrofia muscular pseudo-hipertrófica de Duchenne em pacientes do sexo feminino.

\section{Duchenne muscular dystrophy in a girl with chromusome translocation.}

SUMMARY - It is reported the case of an 8-year-old girl with clinical and laboratory findings suggestive of Duchenne muscular dystrophy who had a chromosome translocation involving the $\mathrm{X}$ chromosome, $46, \mathrm{X}, \mathrm{t} / \mathrm{Bp}+, \mathrm{Xq}-)$. A review about Duchenne muscular distrophy $: \mathrm{n}$ females is made, with emphasis about chromosome abnormalities, mainly chromosome translocations.

A distrofia muscular pseudo-hipertrófica de Duchenne é transmitida por herança recessiva ligada ao cromossoma $X$, ocorrendo portanto em pacientes do sexo masculino, podendo as mulheres ser portadoras assintomáticas 14 . No entanto, nos últimos anos, vêm sendo descritos casos em pacientes do sexo feminino que apresentam cromossomas $X$ anormais 1 , translocaçōes cromossômicas 4,9-12,16,23, sindrome de Turner 6 ou mesmo com cariótipo normal 7,13.21. Apesar de ainda não possuir a distrofia muscular um tratamento efetivo, seu diagnóstico adequado é muito importante para o prognóstico, a manutençāo fisioterápica e o aconselhamento genético. Nessas circunstâncias, comumente o neurologista se encontra em dificuldades diagnósticas frente a menina con distrofia muscular, principalmente quando nāo existe história familiar, como ocorre nas mutações "de novo" 20 . Nessas ocasiões, o diagnóstico da doença é mandatório e deixa de ter sentido puramente acadêmico.

Relatamos o caso de uma menina, sem história familiar, que apresenta distrofia muscular de Duchenne e translocação cromossômica, enfatizando a investigação diagnóstica.

\section{OBSERVACAOO}

MRB, 8 anos de iỏade, sexo feminino, branca, Os familiares relatavam que desae a infância ela era «muito mole», lenta com os movimentos, sempre com dificuldades para sentar em cadeiras sem auxílio, nunca tendo conseguido subir escadas scm apoio $e$ tendo quedas frequientes ao deambular ou mesmo quando estava parada em bipedestacāo. Aos 5

Trabalho realizado na Especialidade de Neurologia do Departamento de Clínica Medica da Universidade Federal do Parané (UFPR): * Professor Adjunto de Neurologia; ** Neuropediatra; *** Professora Assistente de Pediatria. 
anos de idade, como persistiam a hipotonia e a astenia, foi investigada por médico, que encontrou elevação dos enzimas séricos. Desde então vem piorando gradativamente e, agora, tem extrema dificuldade para adotar a posiçăo ortostática quando vai ao solo. Deambula com dificuldades, «balancando muito o corpo». Desenvolvimento - Parto e gestaçăo normais. Controle de cabeça aos 3 meses de idade; sentou sem auxílio aos 9 meses; andou com 15 meses; falou palavras isoladas aos 12 meses; formou frases completas aos 24 meses; alimentação com talheres aos 36 meses; passou a abotoar roupas aos 48 meses e consegue dar laços em sapatos desde os 60 meses. História familiar - Pais normais; 4 irmãos do sexo masculino normais; negam casos semelhantes na família. Exame físico - Freqựencia cardiaca 76 bpm. Exame de cabeça, pescoço, torax, pré-córdio, abdômen e extremidades normais. No exame neurológico apresentava ptose palpebral bilateral, facies miopática, atrofia discreta dos músculos da cintura escapular, presença de escapula alada, lordose lombar importante com protrusão abđominal e marcha anserina. A força muscular no deltóide, supra espinhoso, biceps e triceps era grau 4- (MRCM); antebraços e mãos 4+; no ileopsoas 3; no quadriceps 4-; nos tibials anteriores, gastrocnêmios, biceps surais e extensores dos dedos $4-+$. 0 tono estava globalmente reduzido, tendo também arreflexia profunda generalizada, com exceção do reflexo aqufliano que era normoativo. Ao tentar sair do chão, apresentava manobra de Gowers típica. Sensibilidade táctil, dolorosa, vibratória e de poslção segmentar normais.

Investigação - Hemograma, VHS, eletrocardiograma e raio $\mathbf{x}$ de torax normais. Os enzimas séricos estavam elevados (Tabela 1). Eletromiografia: Em repouso, descargas de

Idade

Enzimas 5 anos 8 anos

\begin{tabular}{lcr}
\hline \hline Creatina kinase & 193 & 354 \\
Desidrogenase lática & 4 & 4 \\
Aldolase & 19 & 32 \\
Transaminase oxalacética & 5 & 4 \\
Transaminase glutamico-pirúvica & 5 & 3 \\
\hline
\end{tabular}

Tabela 1 - Caso MRB. Enzimas séricos, idade em que foram dosados e valor correspondente ao número de vezes elevado $\mathrm{em}$ relaça aos valores normais.

alta frequiência no gastrocnêmio direito. Na contração voluntária, a duração média dos potencials voluntários estava reduzida no quadriceps e biceps braquial. Voltagens médias reduzidas no quadriceps, tibial anterior e biceps braquial. Excesso de potenciais polifásicos curtos no quadriceps, tibial anterior, gastrocnemio e biceps braquial. Excesso de potenciais polifásicos longos no tibial anterlor. Aos esforcos recrutamento aumentado no quadriceps, tibial anterior, gastrocnêmio e biceps sural, com potenclais de duraçăo reduzida, baixa voltagem e abundantes em relação ao esforço no quadriceps e biceps braquial. $O$ exame do oponente do polegar foi normal. A impressão foi de comprometimento muscular primário. Velocidades de condução nervosa motora do nervo peroneiro e mediano foram normais. Biopsia do músculo quadriceps: Processada a fresco e pela histoquímica (J7) mostrou importante proliferação de tecido conjuntivo endomisial e moderada infiltraçáo por tecido adiposo. Importante variação no diâmetro das fibras musculares, que apresentavam formato arredondado, sem distribuiçăo especial das fibras tanto atróficas como hipertróficas. Ocasionais fibras necróticas com fagocitose. Presença de fibras basofílicas e raras fibras enrodilhadas. Presença de todos os tipos de fibras nas ATPases. Aumento importante da atividade da fosfatase ácida em inúmeras fibras (positivas), bem como aumento focal em fibras e nas células fagocitárias. Inúmeras fibras positivas na fosfatase alcalina. A impressão fol de miopatia crónica ativa, sugestiva de distrofia muscular. Cariótipo: Foram analisadas 20 células após coloração pelo método convencional de Moorehead e col., cariotipando algumas células, que mostraram a presença de 46 cromossomas em cada célula, existindo translocação entre um cromossoma do grupo $B$ e um cromossoma do grupo $C$, sugerindo constituiçăo cromossômica $46, \mathrm{X}, \mathrm{t}(\mathrm{Bp}+, \mathrm{Xq}-$ ). (Fig. 1). O cariótipo do pai fol $46, \mathrm{XY}$ e da mãe $46, \mathrm{XX}$. 


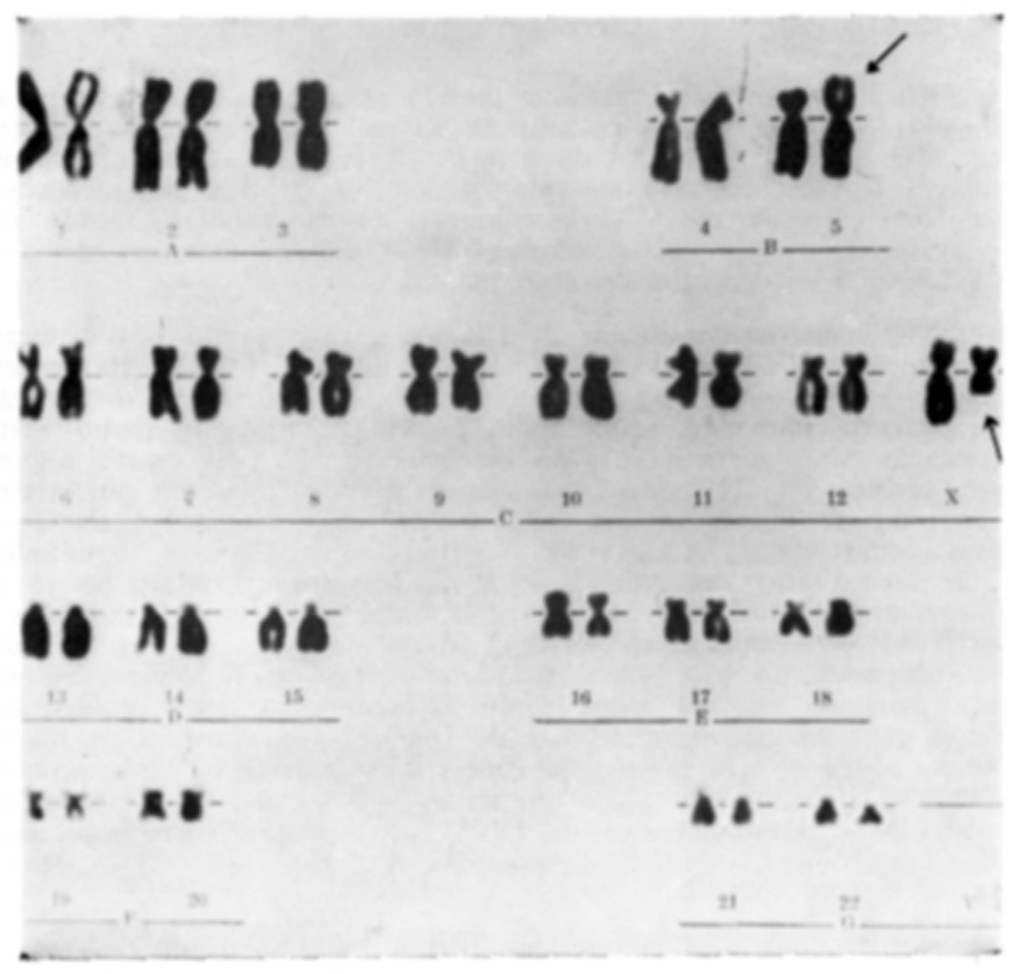

Fig. 1 - Caso MRB. Cariótipo demonstrando a translocação de material de um dos cromossomas $X$ para um dos cromossomas do grupo $B$ : $t(B p+, X q-)$.
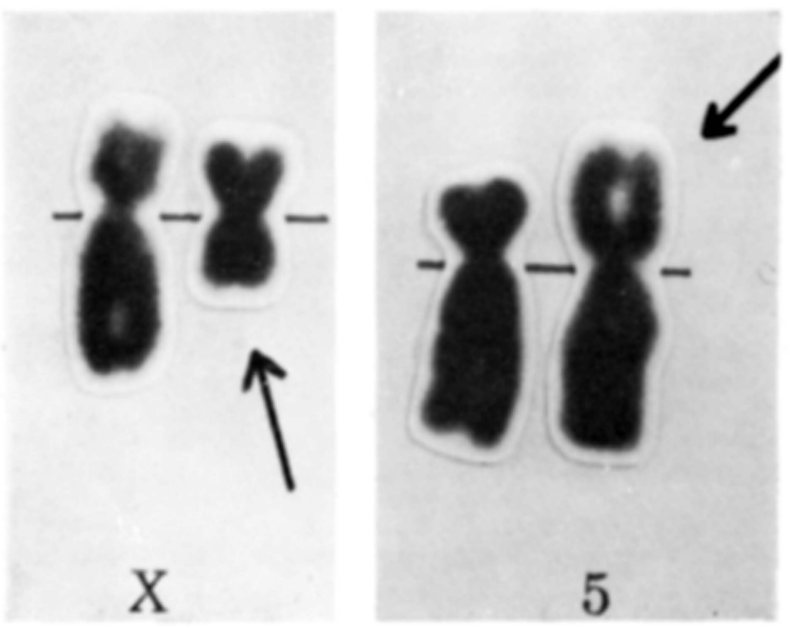

Fig. 2 - Chaso MRB. Detalhe ampliado da figura anterior: $\boldsymbol{X} \boldsymbol{e}$. 


\section{COMENTARIOS}

A incidência da distrofia muscular pseudo-hipertrófica de Duchenne é de um caso para cada 3300 nascimentos do sexo masculino, sendo que uma cm cada 2500 meninas nascidas vivas é portadora do gene 14. A ausência de história familiar não afasta o diagnóstico de distrofia muscular pseudo-hipertrófica de Duchenne, pois a incidência de mutações "de novo" varia conforme a série estudada, sendo atualmente aceito que um terço dos casos são mutações $5,8,14,22$, determinando em média um novo caso em cada 10000 nascimentos do sexo masculino.

Os casos de distrofia muscular de Duchenne em meninas são explicados pela falta de inativação de um dos cromossomas $X$ na fase precoce da embriogênese, conforme hipótese de Lyon. Este cromossoma que não foi inativado, poderá carrear o gene da distrofia muscular, sendo estes pacientes raramente muito afetados na infância, podendo parar a ambulação na jdade adulta 7,14. Se existir alguma anormalidade no cromossoma $X$ poderá não haver inativação, como por exemplo nos casos de sindrome de Turner em que falta o outro cromossoma $X 6$, ou em casos de translocaçöes cromossômicas sendo então o locus do gene exposto, permitindo o aparecimento da doença 14 . Conseguimos obter da literatura o relato de 15 casos de distrofia muscular de Duchenne em mulheres, causadas por translocaçōes cromossômicas 3,4,9-12,14,16.23; sempre o cromossoma fragmentado foi um dos cromossomas $X$. $O$ ponto de fragmentaçāo é o braço curto do cromossoma $X$, diversos cromossomas autossômicos podendo ser envolvidos como receptores. Esses relatos permitiram deduzir que o gene da distrofia muscular de Duchenne se encontra no nivel Xp21 e que a ruptura ou a inativaçāo normal do gene correspondente no outro cromossoma $X$ não se efetuou e permitiu o aparecimento da doença na mulher. Ëstudos utilizando técnicas modernas de recombinaçāo de DNA demonstraram com segurança que 0 gene se localiza no braço curto do cromossoma $X$ a nivel $X p 218,15,18$, mas especificamente na sub-banda Xp2122.

No presente relato, a fragmentaçāo ocorreu em um dos cromossomas $X$. com transposição do material para um cromossoma do grupo B, fomando configuração $46 \mathrm{X}, \mathrm{t}(\mathrm{Bp}+, \mathrm{X}-)$. As técnicas de bandeamento foram prejudicadas por problemas técnicos e, portanto, nảo foi possivel identificar corretamente o nivel. Assim, frente a uma paciente com diagnóstico clínico de distrofia muscular, mesmo sem histćria familiar, a investigação com cariótipo, permitirá aconselhamento genético adequado e permitirá orientar o manejo fisioterápico do paciente e o apoio a longo prazo para a familia.

\section{REFERENCIAS}

1. Berg BO, Conte F - Duchenne muscular dystrophy in a female with a structurally abnormal X-chromosome. Neurology 24:356, 1974.

2. Boyd $\mathbf{Y}$, Buckle VJ - Cytogenetic heterogeneity of translocations associated with Duchenne muscular dystrophy. Clin Genet 29:108, 1986.

3. Dubowitz V - X-autosome translocations in females with Duchenne muscular dystrophy. Nature 322:291, 1986.

4. Emanuel BS, Zackay EH, Tucker SH - Further evidence for Xp21 location of Duchenne muscular dystrophy (DMD) locus: $\mathrm{X} ; 9$ translocation in a female with DMD. J Med Genet 20:461, 1983.

5. Engel AG - Duchenne dystrophy. In Engel AG, Banker BQ - Myology, Basic and Clinical. McGraw-Hill, New York, 1986.

6. Ferrier P, Bamatter F, Klein D - Muscular dystrophy (Duchenne) in a girl with Turner's syndrome. J Med Genet 2:38, 1965.

7. Gómez MR, Engel AG, Dewald G, Peterson HA - Failure of inactivation of Duchenne dystrophy X-chromosome in one female identical twins. Neurology 27:537, 1977.

8. Hejtmancik JF, Harris SG, Tsao CC, Caskey CT - Carrier diagnosis of Duchenne muscular dystrophy using restriction fragment lenght polymorphisms. Neurology $36: 1553$, 1986. 
9. Jacobs PA. Hunt PA, Mayer M, Bart RD - Duchenne muscular dystrophy (DMD) in a female with $\mathrm{X}$ /autosome translocation: further evidence that the $\mathrm{DMD}$ locus is at Xp21. Am J Hum Genet 33:519, 1981.

10. Nevin NC, Hughes AE, Calwell $M$, Lim JHK - Duchenne muscular dystrophy in a female with a translocation involving Xp21. J Med Genet 23:171, 1986.

11. Ribeiro MCM, Melaragno MI, Schmidt B, Brunoni D, Gabbai AA, Hackel C - Duchenne muscular dystrophy in a girl with an $(X ; 15)$ translocation. Am $J$ Med Genet 25:231, 1986.

12. Saito AT, Kimura $\mathrm{S}$, Misugi N, Sugita $\mathrm{H}$ - High-resolution banding study of a $\mathrm{X} / \mathrm{A}$ translocation on a female with Duchenne muscular dystrophy. Hum Genet 71:370, 1985.

13. Somer H, Voutilainen A, Knuutila S, Kaitila I, Rapola J, Leinonen H - Duchenne-like muscular dystrophy in two sisters with normal karyotypes: evidence for autoscmal recessive inheritance. Clin Genet $28: 151,1985$.

14. Thompson MW - The genetic transmission of muscle diseases. In Engel AG, Banker BQ (eds): Myology, Basic and Clinical. McGraw-Hill, New York, 1986.

15. Thompson MW, Ray PN, Bellfall B, Duff C, Logan C, Oss I, Fischbeck KH, Sylvester J, SchmickeI RD, Worton RG - Linkage analysis of a marker localized close to the breakpoint of an $\mathrm{X} ; 21$ translocation with Duchenne muscular dystrophy. Muscle \& Nerve 9 (supl):230, 1986 .

16. Verellen-Dumoulin C, Freund M, Meyer R, Laterre C, Frederic J, Thompson MW, Markovic VD - Expression of an X-linked muscular dystrophy in a female due to translocation involving XP21 and non-random inactivation of the normal $\mathrm{X}$ chromosome. Hum Genet 67:115, 1984.

17. Werneck LC - O valor da biópsia muscular em neurologia: análise de 290 exames a fresco e pela histoquimica. Rev Bras Clin Terap 10(ed especial):2, 1981.

18. Wilcox DE, Cooke A, Colgan J, Boyd E, Aitken A, Sinclair L, Glasgow L, Stephenson JBP, Ferguson-Smith MA — Duchenne muscular dystrophy due to familial Xp-21 deletion detectable by DNA analysis and flow cytometry. Hum Genet 73:175, 1986.

19. Wulfsberg EA, Skoglund RR - Duchenne muscular dystrophy in a 46 XY female. Clin Pediat 5:276, 1986.

20. Yasuda $\mathrm{N}$, Kondo $\mathrm{K} \rightarrow$ No sex difference in mutation rate of Duchenne muscular dystrophy. J Med Genet 17:106, 1980.

21. Yoshioku M, Itagaki $Y$, Saida K, Nishitani $\mathbf{Y}-$ Clinical and genetic studies of muscular dystrophy in young girls. Clin Genet 29:137, 1986.

22. Zatz M - Frequency of Duchenne muscular dystrophy carriers. Muscle \& Nerve 9(supl): $230,1986$.

23. Zatz M, Vianna-Morgante AM, Campos P, Diament AJ - Translocation (X;6) in a female with Duchenne muscular dystrophy: implications for the localisation of the DMD locus. I Med Genet 18:442, 1981. 